\title{
Covid-19 Döneminde Uzaktan Eğitimde Mentor Gerekliliğinin Makine Öğrenmesi Yaklaşımları ile Belirlenmesi ve Belirleyicilerin Açıklanması
}

\author{
Ebru Şimşek ${ }^{1}$, Pelin Canbay ${ }^{2 *}$ \\ ${ }^{1}$ Sütçü İmam Üniversitesi, Mühendislik-Mimarlık Fakültesi, Bilgisayar Mühendisliği Bölümü, Kahramanmaraş, Türkiye (ORCID: 0000-0003-1214-416X), \\ ebrusimsek201@gmail.com \\ ${ }^{2}$ Sütçü İmam Üniversitesi, Mühendislik-Mimarlık Fakültesi, Bilgisayar Mühendisliği Bölümü, Kahramanmaraş, Türkiye (ORCID: 0000-0002-8067-3365), \\ pelincanbay@ksu.edu.tr
}

(3rd International Congress on Human-Computer Interaction, Optimization and Robotic Applications June 11-13, 2021)

(DOI: 10.31590 /ejosat.948242)

ATIF/REFERENCE: Şimşek, E. \& Canbay, P. (2021). Covid 19 Döneminde Uzaktan Eğitimde Mentor Gerekliliğinin Makine Öğrenmesi Yaklaşımları ile Belirlenmesi ve Belirleyicilerin Açıklanması. Avrupa Bilim ve Teknoloji Dergisi, (26), $247-255$.

$\ddot{O} \mathbf{z}$

Covid-19 salgını, dünya genelinde ciddi yaşam kaybına neden olmuş ve Mart 2020'de bu salgın süreci pandemi olarak tanımlanmıştır. Hastalığın yayılımını engelleyebilmek için Covid-19 kısıtlamaları kapsamında eğitim kurumları acilen uzaktan eğitime geçmiştir. Öğrenciler tüm uyaran ve disiplinlerin kendi kontrol ve sorumluluklarına bağlı kaldığı bu süreçte normalden çok daha fazla adaptasyon sorunu yaşamaktadır. Farklı yaşam koşullarında yeterli motivasyonu sağlayamayan öğrenciler online derslere uyum göstermekte büyük oranda zorluk çekmektedir. Söz konusu zorluğu azaltabilmek adına bu makalede, öğrencilerin motivasyon ihtiyaçları doğrultusunda bir mentor tarafından desteğe ihtiyaç duyup duymadıklarını makine öğrenmesi yaklaşımları kullanılarak tespit eden bir çalışma yürütülmüştür. Bu çalışma ile sosyal farkındalık arttırılarak mentor kavramı ile öğrencilere dışsal motivasyon sağlanıp firsat eşitliği sunulması amaçlanmaktadır. Çalışma kapsamında Ürdün Üniversitesi öğrencilerine yapılan anket veri kümesi olarak kullanılmış, çeşitli makine öğrenmesi algoritmaları kullanılarak deneyler yapılmış ve elde edilen sonuçların karşılaştırmalı analizi yapılmıştır. Analiz sonucu Destek Vektör Makinesi \%95 F1 skoru ile bu problem için en yüsek başarıyı üreten sınıflandırıcı olarak tespit edilmiştir. Çözümü modellemek için kullanılan diğer sınıflandırıcılardan da yakın sonuçlar elde edilmiştir. Diğer taraftan Karar Ağaçları algoritmasının açıklanabilirlik yapısı kullanılarak sınıflandırmadaki en etkili belirleyiciler bulunmuştur. Böylece mentor gerekliliğinin tespiti için öğrencilere uzun anketler uygulamanın mümkün olmadığı durumlarda, en verimli sonucu alabilecek belirleyicilerin kullanımı tercih edilebilecektir. Yapılan çalışmada mentor gerekliliğinin tespitinde kullanılabilecek en etkili belirleyici olarak, öğrencilerin "E-öğrenme sistemini kullanmak üretkenliğimi artırıyor.” seçeneğine vermiş oldukları cevap tespit edilmiştir. Çalışma kapsamında belirleyicilerin etkililik hiyererşisi en yüksekten başlayarak ilk üç seviyeye göre ayrıntılandırılmış, uygulamanın olanağına göre tercihe sunulmuştur.

Anahtar Kelimeler: Açıklanabilirlik, Covid-19, Makine Öğrenmesi, Mentorlük, Pandemi

\section{In Covid-19 Period Determining the Mentor Requirement on Distance Education with Machine Learning Approaches and Explanation of the Determinants}

\begin{abstract}
The Covid-19 outbreak caused serious loss of life worldwide, and this epidemic period was defined as a pandemic in March 2020. In order to prevent the spread of the disease, educational institutions urgently switched to distance education within the scope of Covid19 restrictions. Students experience much more adaptation problems than usual in this period of time in which all stimuli and disciplines depend on their control and responsibilities. Students who cannot provide sufficient motivation in different life situations have great difficulty in adapting to online courses. In order to reduce this difficulty, a study was conducted in this paper to determine whether students need support from a mentor in line with their motivational needs, using machine learning approaches. This study aims to
\end{abstract}

*Sorumlu Yazar: pelincanbay@ksu.edu.tr 
provide equality of opportunity by increasing social awareness and providing external motivation to students by the concept of the mentor. Within the scope of the study, a questionnaire for the students from The University of Jordan was used as a data set, experiments were carried out using various machine learning algorithms, and the comparative analysis of the results obtained was made. As a result of the analysis, the Support Vector Machine was determined as the classifier that produced the highest success for this problem with a 95\% F1 score. Similar results were obtained from other classifiers used to model the solution. On the other hand, by using the explainability structure of the Decision Trees algorithm, the most effective determinants in classification were found. Thus, in cases where it is not possible to apply long questionnaires to students to determine the mentoring requirement, the use of determinants that can get the most efficient result can be preferred. In the study, the most effective determinant that can be used in determining the mentoring requirement is the answer students gave to the option of "Using the e-learning system increases my productivity" was determined. Within the scope of the study, the effectiveness hierarchy of the determinants was detailed until the first three levels, starting from the highest, and presented to the preference according to the possibility of the application.

Keywords: Covid-19, Explainability, Machine Learning, Mentorship, Pandemic.

\section{Giriş}

Koronavirüsler, hayvanlarda veya insanlarda hastalığa neden olabilecek büyük bir virüs ailesidir. En son keşfedilen koronavirüs hastalığ1 üst solunum yolu hastalı̆̆ olup COVID-19 olarak isimlendirilmiştir. Yüksek oranlarda can kayıplarına neden olması sebebiyle Dünya Sağlık Örgütü tarafindan 12 Mart 2020 de COVID-19 salgını pandemi olarak ilan etmiştir. $\mathrm{Bu}$ sebeple devletlerce hastalığın yayılımına, bulaş ortamına ve vaka yoğunluğuna sebep olabilecek durumlara karşı çeşitli önlemler alınmış ve milletler bu kısıtlamalarla yaşamaya başlamıştır. (Bingöl Schrijer, 2020; Bostan ve ark., 2020; Atasoy ve ark.,2020)

Pandemi nedeniyle alınan önlemler mümkün olduğunca evde kalmak, kalabalık ortamlara girmemek, insanlarla araya sosyal mesafe koymak, belirtiler varsa karantina uygulamak gibi sıralanabilir. Bu kısıtlamalarla beraber yaşayabilmek için "yeni normal" diye bir kavram türemiştir. İnsanlar yeni normal ile eski alışkanlıklarının dışında, sosyal ortamlardan uzak mümkün olduğunca evde yaşamaya başlamışlardır. İnsan sosyal bir varlık olduğundan bu durum psikolojilerini de etkilemiştir. İş, okul, günlük hayatta rutin işlerine devam ederken motivasyon bulmakta zorlanmışlardır (Bingöl Schrijer, 2020; Bostan ve ark., 2020; Atasoy ve ark., 2020).

İnsanların bireysel gelişimi ve bireysel tatmini için güdüleyici iç ve dış motivasyon gerekmektedir. İçsel motivasyon insanın kendinin farkında olarak, kendini tanıyarak hedeflerine ulaşmak için kendinden güç bulması demektir. İçsel motivasyon sağlayan iyi stresle öğrenci ders çalışmaya motive olabilmektedir. Dışsal motivasyon ise dişardan gelen maddi yada sözlü uyaran aracılığıyla hedefine ulaşmak için insana güç kazandırılması demektir. Öğrencilerin dişsal motivasyon sağlayan çevresindeki insanların etkisi ile eğitimle olan bağları şekillenmektedir. Çevrelerinde kendilerini çalışmaya teşvik eden kişiler bulunan öğrenciler daha başarılı sonuçlar almaktadır. Çevreden gelen bu teşvik ile hedeflerine ulaşmak için öğrencilere güç kazandırılmış olur. Çevrelerinde kendilerini çalışmaya teşvik eden kişiler bulunan öğrenciler daha başarılı sonuçlar almaktadır. Ancak Covid-19 kısıtlamaları nedeniyle geçilen online eğitimde dış uyaranlar azalmış, bu sebeple motivasyon kaynağı oranları değişmiş içsel motivasyon ön plana çıkmıştır. Dışsal motivasyona fazla gereksinim duyan insanın sosyal bir varlık olması da bu durumu zorlaştırmaktadır. Sorumluluk bilincinin yeni yeni geliştiği öğrencilerin kendi kendini kontrol edebilmesi oldukça güçtür. Ne yazık ki farklı yaşam koşullarında bu duruma adaptasyon sağlayıp içsel motivasyon göstermek daha da zor olmaktadır. Uzaktan eğitime hızlı geçiş süreci bu durumu daha görünür kılmıştır (Bingöl Schrijer, 2020; Atasoy ve ark.,2020; Tohidi \& Jabbari 2020; Dede \& Argün, 2004).
Okullar da sosyal iletişimin fazla olduğu alanlardır. Pandemi ilanıyla birlikte tüm dünyada okullar acilen uzaktan eğitime geçmiştir. Dersleri öğretmenler ya çevrimiçi ortamlarda sanal sınıflarda ya da uzaktan eğitim sistemine yüklediği videolar üzerinden işlemektedir. Öğrenciler ve öğretmenler birbirleri için bedensel varlıklarından uzaklaşıp soyut bir varlığa dönüşmüştür. Sınıf ortamında arkadaşlarıyla ders dinleyen öğrenciler, evde tek başlarına ders dinler hale gelmiştir. Öğretmen gözetiminin olmadığı, arkadaş etkileşiminin azaldı $\breve{g}_{1}$ bu yeni sistem kısa süreli kalmayıp zorunlu eğitim biçimine dönüşmüştür. Bu yeni eğitim biçimi kimi öğrenciler için fayda sağlarken kimi öğrencilere iyi gelmemiştir. Derslere çalışacak gerekli motivasyonu sağlayabilmek kişiden kişiye değişmektedir. İçsel motivasyonu yüksek öğrenciler duruma kolay adapte olabilmişken içsel motivasyonu düşük olanlar duruma adapte olamamıştır. Bu durum covid olmayan yıllarla firsat eşitsizliği yaratmış eğitim kalitesi etkilenmiştir. Böylece içsel motivasyonu yüksek öğrenciler ile içsel motivasyonu düşük ögrrenciler arasında adaletsiz bir durum ortaya çıkmıştır. Öğrenci sayısının fazlalığı ve öğretmenlerin yoğunlukları düşünüldüğünde onlara dışsal motivasyon sağlayacak eğitim ortamı sağlamak güçtür (Bingöl Schrijer, 2020; Tohidi \& Jabbari 2020; Aboagye ve ark.,2021; Horita ve ark., 2021; Cicha ve ark., 2021).

Yapılan çalışmalarda mentorlük denilen gönüllü destek ağının verimliliği artırmada etkili olduğu görülmüştür. $\mathrm{Bu}$ gönüllük ağ1 mentor denilen rehber ve mentii denilen danışanlardan oluşur. Daha deneyimli ve bilgili kişiler olan mentorler daha az deneyimli ve daha az bilgili danışanlarına (menti) rehberlik yapmaktadır. Okul hayatı düşünüldüğünde daha bilgili bir akran ya da üst sınıflar bu gönüllülük ağına uygundur. Herhangi bir konuda daha bilgili akranların yada üst sınıfların sağlayacağ1 mentor desteği ile öğrencilere dışsal bir motivasyon kaynağ1 sunulabilmektedir. Böylece uzaktan eğitimde Covid-19 kısıtlamalarında eğitim almak zorunda olan öğrencilerin diğer dönemlerde eğitim alan yaşıtlarına göre azalan eğitim kalitesi yükseltilebilir (Andrews \& Wallis, 1999; Lee \& Bush, 2003; Wilkes, 2006; Garcia ve ark. ,2021; Müller ve ark. , 2021; Tibingana ve ark. , 2020; Fayram ve ark. , 2018; Packham \& Miller, 2000; Ruane, 2012).

Covid-19 süreci gereği uygulanan kısıtlamalar dolayısı ile öğrencilerin farklı yaşam koşullarında eğitim görmek zorunda olması eğitimde firsat eşitsizliğine neden olmaktadır. Bu çalışma, eğitimde meydana gelen bu eşitsizliğe sosyal farkındalığı artırıp, motivasyon gerektiren öğrencilerin tespit edilmesini ve mentorluk kavramı ile eğitim kalitesinin Covid-19 sürecine adaptasyonunu sağlamayı amaçlamaktadır. Böylece içsel motivasyonu yüksek öğrenciler ile içsel motivasyonu düşük öğrenciler arasındaki pandemi süreci kısıtlamalardan kaynaklı, eğitimdeki adaletsizliğin ortadan kaldırılmasına katkı sunacaktır. $\mathrm{Bu}$ çalışmada ayrıca mentor gerekliliğini belirten en etkili belirleyiciler, Karar Ağacı algoritmasının açıklanabilirlik yapısı 
kullanılarak tespit edilmiştir. Bu tespit ile öğrencilere uzun anketler yapmanın mümkün olmadığ 1 durumlar da bile mentor gerekliliği tespiti etkili bir şekilde yapılabilir olmaktadır.

\section{2. İlgili Çalışmalar}

Pandemi sürecinde eğitimde karşılaşılan zorlukların azaltılmasına yönelik birçok bilimsel çalışma yürütülmüştür. Yürütülen çalışmaların önemli bir kısmı bu süreçte karşılaşılan performans, motivasyon ve başarı düşüklügü̈ ile ilgilidir. Bizim de bu çalışmada ele aldığımız gibi, pandemi sürecinde karşıllaşılan zorlukların bir nebze olsun giderilebilmesi için yapılan bazı etkili çalışmalar aşağıda özetlenmiştir.

Dias ve arkadaşları (2020), Covid - 19 çağında çevrimiçi öğrenmeyi desteklemek için derin öğrenme tahmin modeli DeepLMS geliştirmiştir. Bu model öğrenenlere üstbilişsel uyaran sağlamak ve eğitimcileri olası motivasyon eksiklikleri, ders odaklanma, henüz yayınlanmamış çevrimiçi kurs etkileşiminin benimsenmesi konusunda zamanında bilgilendirmek böylece önleyici ve düzeltici müdahaleler için uyarıda bulunmak amacıyla geribildirim sunmaktadır.

Agarwal ve arkadaşları (2021), çalışmalarında COVID-19 kısıtlamaları sırasında e-öğrenme araçlarının Hintli öğrenciler arasında verimliliğini ve kabul edilebilirliğini istatistiksel olarak analiz etmiştir. Öğrencilerin çoğunun normal sınıf eğitimlerinde e-öğrenme platformu özelliklerini benimsedikleri bulunmuş.

Ahmet ve Malik (2020), çalışmalarında yüksek eğitim kurumlarında, COVID-19 döneminde stratejik karar vermek için makine öğrenmesi algoritmalarının performansını araştırmıştır. Random Forest algoritma performansının Destek Vektör Makinesi, Karar Ağacı ve Navie Bayes'e kıyasla daha yüksek olduğunu göstermişlerdir.

$\mathrm{Lu}$ ve arkadaşları (2020), çalışmalarında e-öğrenimin kabulünü etkileyen faktörleri makine öğrenimi algoritması yaklaşımı ile araştırmıştır. Çalışmada kümeleme ile geleneksel öğrenme, e-öğrenme ve hibrit öğrenme șeklinde sınıflar belirlenip sınıflandırma algoritmaları ile model geliştirilmiştir. Öğrencilerin uygun bir öğrenme yöntemi seçmelerine yardımcı olan tahmin sonuçlarının doğruluğu $\% 81,52$ bulunmuştur.

Feldman ve arkadaşları (2020), çalışmalarında mentor/menti etkileşimlerini inceleyerek mentorlüğün gerekliliğini istatistiksel yöntemlerle araştırmıştır. Mentorlu öğretim üyelerinin, çalışmalarının dağılımından daha fazla memnun olduklarını ve mentor olmayanlara göre daha yüksek öz yeterliklere sahip olduklarını göstermektedir.

Rodger ve Tremblay (2003), çalışmasında akran mentorluk programının üniversite birinci sınıf öğrencilerinde akademik başarıya etkisini istatistiksel yöntemlerle incelemiştir. Mentorluk yapılan gruptaki yüksek kaygılı öğrencilerin, düşük kaygılı öğrencilere göre daha başarı gösterdiği gözlemlenmiş, mentorlük yapılmayan kontrol grubunda ise yüksek kaygılı öğrencilerin, düşük kaygılı öğrencilere göre daha az başarı gösterdiği bulunmuştur.

Van Esch ve arkadaşları (2021), COVID-19 salgını endişeleri ve cinsiyetin mentor arayan davranış ve öz yeterlik üzerindeki etkisini istatistiksel yöntemlerle incelemiştir. Çalı̧̧mada 253 akademisyenden toplanan verileri analiz etmektedir. Sonuçları kadınların COVID-19 salgını hakkında daha fazla endişe duymaları nedeniyle daha fazla mentorluk istediğini göstermiştir.

Xu ve arkadaşları (2020), çevresel uyaranlarının COVID-19 bağlamında akran referansları arasındaki ilişki, algılanan yakınlık ve algılanan kontrol ve e-öğrenme katılımı üzerindeki etkisini incelemiştir. Çalışmada 377 üniversite öğrencisinden alınan veriler kullanılmıştır ve istatistiksel olarak PLS-SEM ile analiz edilmiştir. Sonuç olarak e-öğrenmede algılanan yakınlık, algılanan kontrol ve akran referanslarının öğrencilerin öz yeterlik ve refahını olumlu yönde etkilediğini ve öğrenme hevesinin arttığını göstermiştir.

Kapasia ve arkadaşları (2020) COVID-19 ortasında kilitlenmenin Batı Bengal'deki çeşitli kolej ve üniversitelerin lisans ve lisansüstü öğrencileri üzerindeki etkisini değerlendirmiştir. 232 öğrencinin katıldığı anket veri kümesi olarak kullanılmış ve SPSS ile istatiksel analiz yapılmıştır. Öğrencilerin \% 70'inin e-öğrenmeye katılabildiği, çoğunun eöğrenmeye katılmak için android mobil kullandığı bulunmuş. Öğrencilerde depresyon kaygısı, zayıf internet bağlantısı ve evde olumsuz çalışma ortamı gibi çeşitli sorunlar bulunduğu tespit edilmiş. Sonuç olarak uzak bölgelerden ve dışlanmış kesimlerden gelen öğrencilerin, bu salgın sırasında çalışmak için büyük zorluklarla karşılaşmakta olduğu ve firsat eşitsizliği yaşadığı görülmüştür.

\section{Materyal ve Metot}

\subsection{Veri Kümesi}

Bu çalışmada, Ürdün üniversitesi öğrencilerine Mart 2020 ve Nisan 2020 arasındaki pandemiye ilk geçiş sürecinde yapılmış bir anketten toplanarak hazırlanmış olan e-öğrenme veri kümesi kullanılmıştır (Al-Okaily ve ark. , 2020a, 2020b). Anket öğrencilerin demografik özellikleri ve e-öğrenme sistemini kullanmalarına ilişkin bakış açılarını sorgulayan soruların cevaplarını içermektedir.

Ham veri kümesi; 587 öğrenci için 6 demografik soru, 20 eöğrenme sorusu ve anket zamanı olmak üzere toplam 27 öznitelik içermektedir. Veri kümesinde her satır, bir kişinin ankete verdiği yanıtı temsil eder. Katılımcıların belirli bir ifadeye ne kadar katıldıklarını veya katılmadıklarını belirtmelerine olanak sağlamak için beş puanlık bir aralık ölçeği uygulanmıştır (AlOkaily ve ark., 2020a). Öğrencilerinin profiline ilişkin veri kümesinin demografik bilgileri Tablo 1'de gösterilmiştir 
Tablo 1. Veri Kümesi Demografik Bilgileri

\begin{tabular}{|c|c|}
\hline Cinsiyet & $\begin{array}{l}290 \text { erkek }(\% 49,4) \\
297 \text { kadın }(\% 50,6)\end{array}$ \\
\hline Yaş & $\begin{array}{l}18-20 \text { yaş arası } 149 \text { kişi }(\% 25,3) \\
21-23 \text { yaş arast } 311 \text { kişi }(\% 52,9) \\
24-30 \text { yaş arast } 100 \text { kişi }(\% 17) \\
30 \text { yaş üstü } 28 \text { kişi }(\% 4,7)\end{array}$ \\
\hline Seviye & $\begin{array}{l}\text { Lisans ögrencisi } 572 \text { kişi }(\% 97,4) \\
\text { Lisansüstü ögrencisi } 15 \text { kişi }(\% 2,6)\end{array}$ \\
\hline Daha önce e-öğrenme kullanma durumu & $\begin{array}{l}\text { Kullanan: } 293(\% 49,9) \\
\text { Kullanmayan: } 294(\% 50,1)\end{array}$ \\
\hline
\end{tabular}

\section{2. Öznitelik Bilgisi}

Bu çalışmada 4 demografik soru ve 20 e-öğrenme sorusu öznitelik olarak kullanılmıştır. Kullanılan öznitelikler Tablo 2'de gösterilmiştir. Demografik sorulara verilen cevaplar kategorik cevaplar içermektedir. Cinsiyet sorusuna erkek ya da kadın şeklinde cevaplar alınmıştır. Yaş sorusu için 18-20 yaş aralığı, 2123 yaş aralığı, 24-30 yaş aralığ 1 yada 30 yaş üstü şeklinde cevaplar alınmıştır. Öğrencilik seviyesi lisans ya da lisansüstü olarak belirtilmiştir. Daha önce e-öğrenme sistemi hizmetlerini kullanma durumu evet ya da hayır şeklinde belirlenmiştir.

E-öğrenme sorularına verilen cevaplar kesinlikle katılmıyorum için 1, katılmıyorum için 2, kararsızım için 3, katılıyorum için 4, kesinlikle katılıyorum için 5 şeklinde numerik olarak alınmıştır. Veri kümesine mentor gerekliliğini belirlemek için etiket sınıfi eklenmiştir. Mentor gerekli için 1, mentor gerekli değil için 0 şeklinde numerik değer olarak eklenmiştir.

Tablo 2. Kullanılan Öznitelikler

\begin{tabular}{|c|c|}
\hline Demografik sorular & Cevaplar \\
\hline Cinsiyet & erkek:1, kadın:0 \\
\hline Yaş & 18-20: 1000, 21-23: 0100, \\
\hline Seviye & lisans $: 1$, lisansüstü :0 \\
\hline Daha önce E-öğrenme sistemi hizmetlerini kullandınız mı? & evet $: 0$, hayır: 1 \\
\hline e-öğrenme soruları & Cevaplar \\
\hline Benim için önemli olan kişiler e-öğrenme sistemini kullanmam gerektiğ & \multirow{10}{*}{$\begin{array}{l}1=\text { kesinlikle } \\
\text { katılmıyorum, } \\
2=\text { katılmıyorum, } \\
3=\text { kararsizım, } \\
4=\text { katıllyorum, } \\
5=\text { kesinlikle katılyyorum }\end{array}$} \\
\hline Davranışımı etkileyen kişiler e-öğrenme sistemini kullanmam gerektiği & \\
\hline Üniversitemde e-öğrenme sistemini kullanan öğrencilerin, kullanmay & \\
\hline Üniversitemde e-öğrenme sistemini kullanan öğrenciler kullanmayar & \\
\hline Arkadaşlarım e-öğrenme sistemini kullanmam gerektiğini düşünür. & \\
\hline Akrabalarım e-öğrenme sistemini kullanmam gerektiğini düşünür & \\
\hline Akranların e-öğrenme sistemini kullanmam gerektiğini düşünür. & \\
\hline Sınıf arkadaşlarım e-öğrenme sistemini kullanmam gerektiğine inanır. & \\
\hline E-öğrenme sistemini kullanmak günlük hayatımda faydalıdır. & \\
\hline E-öğrenme sistemini kullanmak üretkenliğimi artırlyor. & \\
\hline
\end{tabular}




\begin{tabular}{|c|c|}
\hline E-öğrenme sistemini kullanmak zaman kazandırır. & \\
\hline E-öğrenme sistemini kullanmak verimliliğimi artırlyor. & \\
\hline E-öğrenme sisteminin kullanımının kolay olduğunu hissediyorum. & \\
\hline E-öğrenme sisteminin uygun olduğunu hissediyorum. & \\
\hline E-öğrenme sisteminden istediğim bilgiyi elde etmek kolaydır. & \\
\hline E-öğrenme sistemi eğitim gerektirmez. & \\
\hline Gelecekte e-öğrenme sistemini kullanmayı düşünüyorum. & \\
\hline E-öğrenme sistemini mümkün olan her zaman günlük hayatımda kullanırım. & \\
\hline E-öğrenme sistemini sıklıkla kullanmayı planlıyorum. & \\
\hline Yakın gelecekte e-öğrenme sistemini kullanacă̆ımı tahmin ediyorum. & \\
\hline Mentor gerekli mi? & 0: hayır, 1:eve \\
\hline
\end{tabular}

\subsection{Veri Kümesi Önişleme}

Ham veri kümesini analize hazır hale getirmek için ön işlemden geçirilmesi gerekir. Bunun için ham veri kümesinde gerekli görülmeyen öznitelikler çıkarılmıştır. Anketin otomatik kayıt zamanı, öğrencilerin bölümleri ve e-öğrenme kullanma durumu "evet" ise buna bağl1 "ne kullanıld1" sorusunun cevaplarını içeren sütunlar analize katkısı olduğu düşünülmediği için veri kümesinden çıkarılmıştır. Kullanılan öznitelik cinsiyet, yaş, seviye, e-öğrenme geçmişi ve e-öğrenme ile ilgili 20 sorudur. İşlem yapabilmek için veri kümesindeki yazım hataları giderilmiştir. Böylece 587 satırlık, 4 tanesi kategorik değer içeren 24 öznitelikli veri kümesi elde edilmiştir.

Elde edilen veri kümesindeki kategorik verileri numerik verilere dönüştürmek amacı ile; iki değişkenli cevaplar içeren cinsiyet, seviye ve e-öğrenme geçmişi için Label Encoding ile etiket kodlama uygulanmıştır. 4 farklı değişken içeren yaş özniteliğine ise One Hot Encoding ile ikili gösterim sunan kodlama uygulanmıştır. Label Encoding, kategorik değişkenlere sırayla numara verirken, One Hot Encoding, işlenen öznitelik içindeki her bir kategorik değişken için yeni öznitelik oluşturup satırda var olması durunda 1, var olmaması durumunda 0 olacak şekilde ikili temsil imkanı sunar. Böylece kategorik veriler sayısallaştırılmış olur. Label Encoding ile öznitelik sayısı aynı kalırken, One Hot Encoding ile kategorik değişken kadar yeni öznitelik veri kümesine eklenmiştir.

Orijinal veri kümesinde bulunan özniteliklerden "E-öğrenme sistemini kullanmak verimliliğimi artırıyor." olan 12. sorunun cevabı mentor ihtiyacını belirlemek amacı ile veri kümesinin etiketlendirilmesinde kullanılmıştır. Verimliliğin artırmadığını belirten 1-2-3 değerleri için "evet" yani "Mentor gereklidir", verimliliğin artırdığını belirten 4-5 değerleri için "hayır", yani "Mentor gerekli değildir" karşılaştırmaları ile etiketlendirme işlemi yapılmıştır. Mentor gereklidir durumunun etiketi "1", mentor gerekli değildir durumunun etiketi " 0 " olacak şekilde güncellenerek orjinal veri kümesi 2 sınıflı bir veri kümesine dönüştürülmüştür. 12. soru etiket geliştirmede kullanıldığ 1 için ilgili kolon veri kümesinden çıkarılmıştır.

\subsection{Kullanılan Sınıflandırıcılar ve Parametreleri}

Yapay zeka ile karar destek sistemleri gün geçtikçe güçlendirilmektedir. Bu çalışmada da veri kümesindeki veriler arasında insanların algılaması ve hesaplamasının çok zor olduğu örüntülerin bulunmasını sağlayan makine öğrenmesi yöntemleri kullanılmıştır. Veri analizinde denetimli öğrenme modeli yani uzman görüşü ile sınıflandırılmış verilerden öğrenme yapılacağı için algoritmalar buna göre seçilmiştir. Farklı algoritmaların problem özelinde performanslarını karşılaştırabilmek adına K En Yakın Komşuluk (K Nearest Neighbors (KNN)), Destek Vektör Makinesi (Support Vector Machine (SVM)), Naif Bayes (Naive Bayes (NB)), Algılayıcı (Perceptron (P)), Karar Ağacı (Decision Tree (DT)) ve Rastgele Orman (Random Forest (RF)) yöntemleri kullanılmıştır. Sistem veriler ve algoritmalar ile eğitilmiş örüntüler bulunarak modeller geliştirilmiştir. Çalışmanın geri kalanında algoritmalardan bahsedilirken kısaltmaları kullanılacaktır.

Model geliştirilirken kullanılan algoritmaların özellikleri belirlenebilir. Bu çalışmada varsayılan özellikler kullanılmıştır. KNN için komşu sayısı k=5 alınmıştır. Tüm noktalar eşit olarak ağırlıklandırılmıştır. Uzaklık ölçüsü olarak Minkowski kullanılmıştır. SVM için kernel fonksiyonu olarak rbf kullanılmıştır. Kernel fonksiyonunun derecesi 3 alınmıştır. NB için Gaussion Naive Bayes yani normal dağılımlı NB kullanılmıştır. P için maksimum itarasyon sayısı 1000, durdurma kriteri 0.001. Eğitim verileri de her iterasyondan sonra karıştırılmıştır. DT için kriter olarak Gini index kullanılmıştır. Her düğümde bölünmeyi seçmek için en iyi belirleyici seçilmiştir. Dahili bir düğümü bölmek için gereken minimum örnek sayısı 2 dir. Bir yaprak dügümünde olması gereken minimum örnek sayısı 1 dir. Daha sonra bu index ile elde edilen sonuçlar kullanılarak sınıflamanın belirleyicileri açıklanacaktır. RF için ağaç sayısı 100 dür. Kriter olarak yine Gini indexi seçilmiştir. Dahili bir düğümü bölmek için gereken minimum örnek sayısı 2 dir. Bir yaprak düğümünde olması gereken minimum örnek sayısı 1 dir.

\subsection{Sınıflandırıcıların Eğitimi}

Veri kümesi ile sistemi eğitmek için öncelikle eğitim ve test verilerine ayırmak gerekir. Bu sebeple veri kümesi \%80 eğitim 
veri kümesi ve \%20 test veri kümesi olarak 469 eğitim 118 test için kullanılmak üzere ayrılmıştır. Ayrımda rastgelelik sağlanmıştır. Daha sonra sistem eğitim veri kümesi ve algoritmalar ile eğitilerek model geliştirilmiştir.

Kullanılan algoritmaların birbirinden farklı karar yaklaşımları vardır. KNN, sınıfı aranan veriye, dağılım içindeki en yakın $\mathrm{k}$ kadar komşusuna bakarak karar vermeyi sunan algoritmadır. SVM, dağılımı inceleyerek dağılımına göre veri noktalarını belirgin bir şekilde ayıran bir hiper düzlem bulup buna göre sinıflandırma yapar. NB, Bayes olasılık teoremine dayanan hesaplamayla sinıf belirleme yapar. Algılayıcı, tek katmanlı sinir ağı olup belli bir eşik bilgisine göre sınıflandırmaya dayanır. Karar Ăgacı, tepeden aşağı inerek ağaç benzeri model ile karar noktalarında kurala uygun sınıflandırma yapar. RF, çok sayıda karar ağacı inşa edip ortalama bir karar oluşturarak sınıflandırma yapan bir toplu siniflandirıcidir. Sistem bu algoritmaları kullanarak örnek veri kümesi olan eğitim veri kümesi ile eğitilmiş örüntüler bularak modeller geliştirmiştir.

Algoritmalar ile ayrı ayrı geliştirilmiş modeller test verisine uygulanarak test edilmiştir. Geliştirilen modelleri değerlendirmek için hata matrisleri çıkarılmış, model doğruluk (accuracy), kesinlik (precision) ve duyarlılık (recall) ölçülmüş, ayrıca kesinlik ve duyarlılık değerlerinin harmonik ortalamasını veren F1 skoru hesaplanmıştır.

Çalışmada makine öğrenmesi kullanıldığı için probleme en uygun modeli seçmek gerekir. En uygun modelin hangisi olması gerektiğine karar vermek için ise veri kümesindeki sınıf dağılımını incelemek gerekir. Kullanılan veri kümesi sınıf dağılımı incelendiğinde; Mentor gereken 458 öğrenci varken, mentor gerekmeyen 129 öğrenci vardır. Sınıflar arasında fark fazla olmasaydı doğruluk ölçeği en uygun modeli seçerken kullanılabilirdi. Ancak sınıflar arasındaki fark fazladır. Bu sebeple en uygun model F1 skoru ölçeği olarak belirlenmiştir.

Hata matrisleri; Doğru tahmin-sınıf1 (True Pozitif (TP)), Doğru tahmin-sınıf2 (True Negatif (TN)), Yanlış tahmin-sınıf1 (False Pozitif (FP)) ve Yanlış tahmin-sınıf2 (False Negatif (FN)) değerlerini içerir. Bu değerler kullanılarak aşağıdaki fonksiyonlar ile doğruluk, kesinlik, duyarlılık ve F1 skor hesaplanmıştır.

$$
\begin{gathered}
\text { Doğruluk }=\frac{T P+T N}{T P+T N+F P+F N} \\
\text { Kesinlik }=\frac{T P}{T P+F P} \\
\text { Duyarlılık }=\frac{T P}{T P+F N} \\
\text { F1 Skor }=2 * \frac{\left(\frac{T P}{T P+F P}\right) *\left(\frac{T P}{T P+F N}\right)}{\left(\frac{T P}{T P+F P}\right)+\left(\frac{T P}{T P+F N}\right)}
\end{gathered}
$$

Doğruluk, modelde doğru tahminlerin toplam veri kümesine oranıdır. Kesinlik, pozitif yani sınıf1 olarak tahmin edilenlerin gerçekten kaç tanesinin sınıf1 olduğunu gösterir. Duyarlılık, pozitif yani sınıf1 olarak tahmin edilmesi gerekenlerin ne kadarının sınıf1 olarak tahmin edildiğini gösterir. F1 skoru ise Kesinlik ve Duyarlılık değerlerinin harmonik ortalamasını alır böylece hatalı sonuç elde edilmemesi için uç durumlar gözardı edilerek hesaplama yapılır.

\subsection{Belirleyicilerin Açıklanması}

Karar Ağaçları sınıflandırma ve regresyon analizinde sıklıkla kullanılan, ağaç yapısında bir çözüm sunan bir makine öğrenmesi algoritmasıdır. Veri kümesinde bulunan her bir özelliğin o veri kümesindeki ve yapılacak sinıflandırmadaki etkisini bir indexleme ile belirler. Karar ağaçlarında en yaygın kullanılan indexleme yöntemi Gini index'tir.

$$
\operatorname{Gini}(x)=1-\sum_{i(x)} p_{i(x)}^{2}
$$

Verilen formülde $\mathrm{x}$, veri kümesindeki bir öznitelik olmak üzere; $p_{i}$, i sınıfının bu öznitelik etkisi ile gerçekleşme olasılığıdır.

Günümüzde artık birçok alanda yapay zekanın kullanılıyor ve insan hayatını büyük oranda etkiliyor olması, yapay zeka temelli çözümlerin açıklanabilir olması gerekliliğini ortaya çıkarmıştır. İnsanların hayatını bu derece etkileyen sistemlerin kapalı kutu çözümleri bu sistemlere olan güveni azalttığından, yapay zeka algoritmalarının hangi belirleyicilerin etkisi ile problemlere çözüm sunduğunun açıklanabilir olması bir ihtiyaçtır. Bu çalışmada veri kümesi olarak öğrencilere yapılan bir anket kullanılmıştır, fakat her eğitim kurumunun aynı anketi tüm öğrencilerine uygulayarak mentor gereksinimini belirlemesi, özellikle pandemi koşullarında pek mümkün görülmemektedir. Mentor gereksinimini belirlemede en etkili özniteliklerin (bizim çalışmamız için bu öznitelikler sorulardan oluşmaktadır) hangisi/hangileri olduğunun belirlenmesi ile anketin tamamı değil az bir kısmı uygulanarak da gereksinim büyük oranda tespit edilebilecektir. $\mathrm{Bu}$ doğrultuda çalışmamızda, Karar Ăgacı algoritmasının açıklanabilir yapısından faydalanılmıştır. Elde edilen sonuçlar bir sonraki bölümde sunulmaktadır.

\section{Deneysel Sonuçlar ve Tartışma}

Eğitim için ayrılan veri kümesi kullanılarak, daha önce de belirtildiği gibi, 6 farklı makine öğrenmesi yöntemi ile 6 farklı sınıflandırıcı model oluşturulmuştur. Geliştirilen modeller, sınıfları bilinmeyen test verisi ile test edilmiştir. Sınıf tahmini ve gerçek sınıf bilgisinden yola çıkarak hangi algoritmanın probleme özgü daha başarılı olduğunu karşılaştırmaya yarayan model doğruluk oranları elde edilmiştir. Ayrıca algoritmaların hata matrisleri elde edilerek doğru yanlış tahminler karşılaştırılmıştır. Elde edilen sonuçlar Tablo 3'de sunulmuştur.

Tablo 3. Model Test Sonuçlarl

\begin{tabular}{lllll}
\hline Model & $\begin{array}{l}\text { Doğruluk } \\
\text { (Accuracy) }\end{array}$ & $\begin{array}{l}\text { Kesinlik } \\
\text { (Precision) }\end{array}$ & $\begin{array}{l}\text { Duyarlılık } \\
\text { (Recall) }\end{array}$ & F1-score \\
\hline KNN & 0.89 & 0.90 & 0.96 & 0.93 \\
\hline SVM & 0.92 & 0.92 & 0.97 & 0.95 \\
\hline NB & 0.89 & 0.90 & 0.96 & 0.93 \\
\hline P & 0.89 & 0.90 & 0.97 & 0.93 \\
\hline DT & 0.80 & 0.87 & 0.97 & 0.93 \\
\hline RF & 0.88 & 0.91 & 0.93 & 0.92 \\
\hline
\end{tabular}


Tablo 3'te sınıflandırıcıların doğruluk, kesinlik, duyarlılık ve F1 skor ölçümleri verilmiştir. Amaç eşit dağılmayan veri kümesinde model seçiminde hata yapmamaktır. Bu sebeple sınıflandırıcıların F1 skor'larına bakıldığında SVM F1 skoru \%95 ile en yüksek olan sınıflandırıcı model olmuştur. Diğer modellerin
\%93 F1 skoru ile eşit sonuca ulaşması da problemin ve çalışmanın tutarlılığını göstermektedir. Modellerin test sonuçlarını örneklem bazında değerlendirmeye olanak sağlayan hata matrisleri Şekil 1 'de gösterilmektedir.

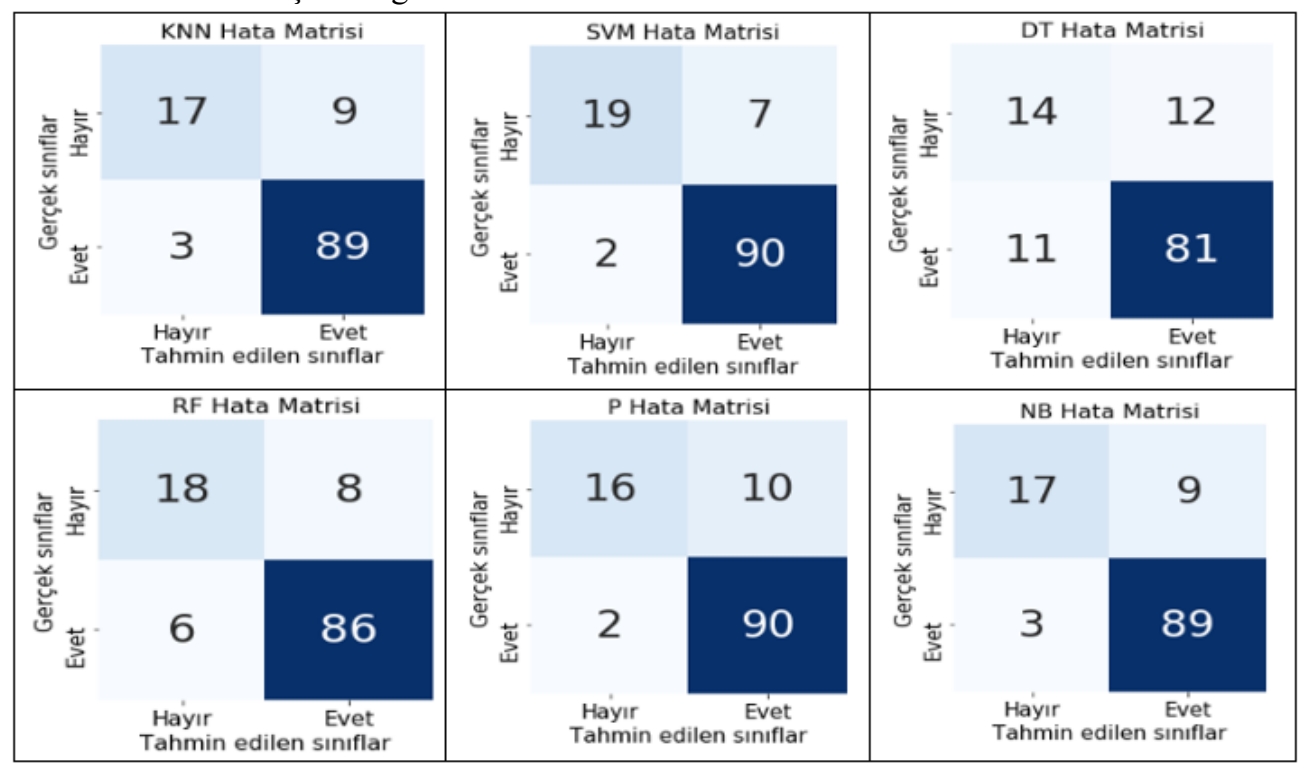

Şekil 1. Model Hata Matrisleri

Toplamda 118 test verisi gerçekte 92 "evet" ve 26 "hayır" sınıfi bulundurmaktadır. Matrisler incelendiğinde modellere için gerçek sınıflara göre doğru ve yanlış tahminler görülebilir. En başarılı modelin SVM olarak bulunduğu bu çalışmada SVM gerçek sınıfı "hayır" olan 17 veriyi "hayır" olarak doğru tahmin ederken, 9 veriyi "evet" olarak yanlış tahmin etmiştir. Gerçek sınıfi "evet" olan 89 veriyi "evet" olarak doğru tahmin ederken, 3 veriyi "hayır" olarak yanlış tahmin etmiştir. SVM model başarısının \%95 olduğu düşünülürse, mentor desteği belirlemek için makine öğrenmesi kullanmak elverişlidir.
Sınıflandırıcı model olarak Karar Ağaçları en düşük doğruluk değeri üretmiş olmasına rağmen SVM'den sonraki en yüksek F1 skorlarından birini üretmiştir. Diğer modeller ile kıyaslandığında sadece SVM ile bir miktar yüksek başarı elde edilmiştir. Dolayısı ile ele aldığımız problem özelinde açıklayıcı olarak Karar Ağacı düğümlerini ve bu düğümlerin Gini indexlerine bağlı hiyerarşisini kullanmak çözüme giden yolu açıklamak için yeterli olacaktır. Karar Ağacı algoritmasından elde edilen ağaç yapısının bir kısmı Şekil 2'de gösterilmektedir.

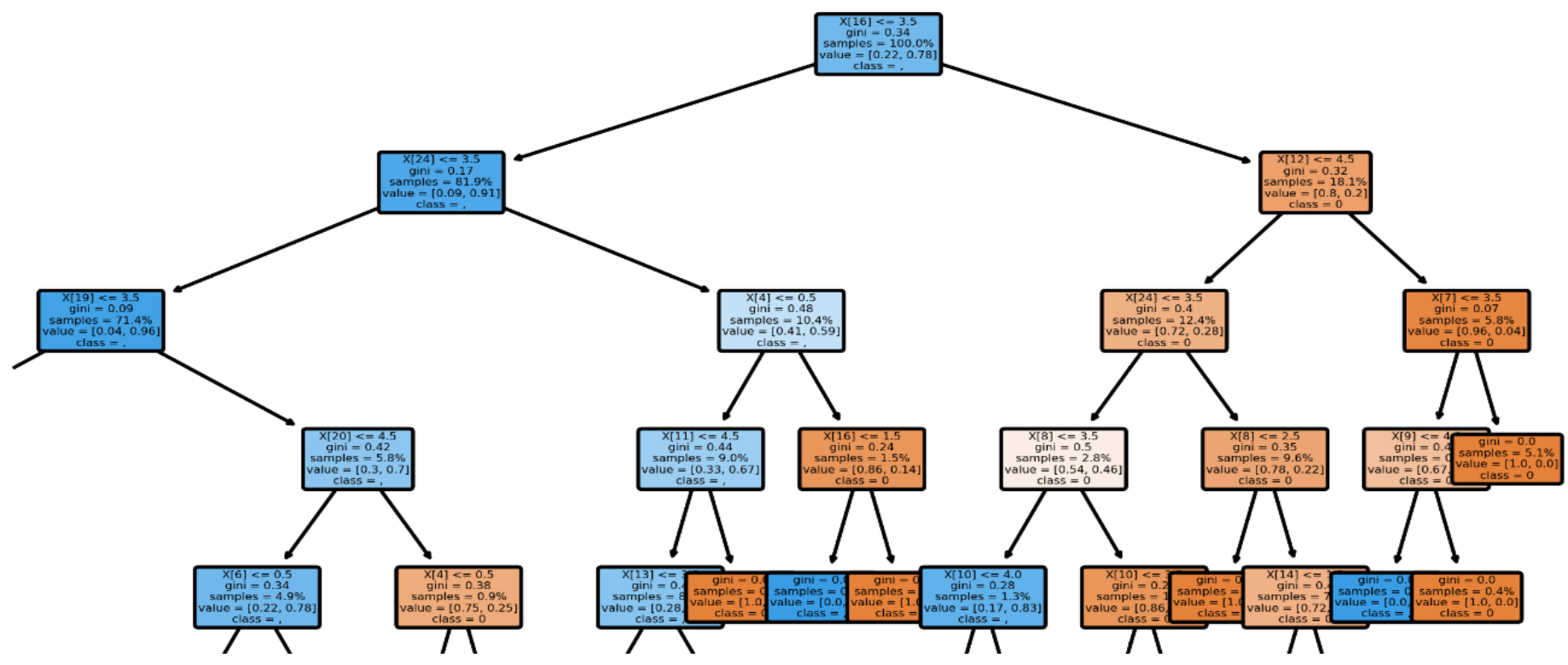

Şekil 2. Üretilen Karar Ağacının Bir Kısmı

Karar Ağacı algoritması probleme özgü geniş ve çok katmanlı bir çözüm üretmiştir. Elde edilen çözümün ilk üç katmanı, verilen karar ile ilgili önemli bilgiler vermektedir. Karar ağacının ilk üç katmanını oluşturan, yani sınıflandırıcının kararını e-ISSN: 2148-2683 belirleyen en önemli 7 belirleyici, Gini indexleri ve hangi bilgiyi içerdiği önem sırasına göre Tablo 4'te gösterilmektedir. 
Tablo 4'te görüldüğü gibi, kullandığımız veri kümesinde ele aldığımız problemin çözümünü sağlamaya yardımcı en etkili belirleyici, öğrencilerin "E-öğrenme sistemini kullanmak üretkenliğimi artırıyor.” seçeneğine verdikleri cevap olmuştur. İndexleme işlemi her seviyede ayrı yapıldığından, index değerleri seviyelerine göre önem kazanmaktadır.

Tablo 4. Sinfflandırma Kararının En Etkili Belirleyicileri

\begin{tabular}{lll}
\hline Öznitelik & Gini index değeri & Özniteliğin İçerik Bilgisi \\
\hline$X[16]$ & 0,34 (1. seviye) & E-öğrenme sistemini kullanmak üretkenliğimi artırıyor. \\
\hline$X[12]$ & 0,32 (2. seviye) & Akrabalarım e-öğrenme sistemini kullanmam gerektiğini düşünür \\
\hline$X[24]$ & 0,17 (2. seviye) & E-öğrenme sistemini sıklıkla kullanmayı planlıyorum. \\
\hline$X[4]$ & 0,48 (3. seviye) & Yaş (30+) \\
\hline$X[24]$ & 0,4 (3. seviye) & E-öğrenme sistemini sıklıkla kullanmayı planlıyorum. \\
\hline$X[19]$ & 0,09 (3. seviye) & E-öğrenme sisteminin uygun olduğunu hissediyorum. \\
\hline$X[7]$ & 0,07 (3. seviye) & Benim için önemli olan kişiler e-öğrenme sistemini kullanmam gerektiğini düşünüyor \\
\hline
\end{tabular}

\section{Sonuç}

Eğitimde başarı yüksek oranda öğrencilerin motivasyonuna ve adaptasyona bağlıdır. Covid 19 salgını ile birlikte uzaktan eğitime geçilmesiyle, hem dışsal motivasyon kaybına uğrayan hem de birçok harici uyaranla tek başına mücadele etmek zorunda olan öğrenciler beklenmedik başarısızlıklarla karşılaşmaktadır. $\mathrm{Bu}$ çalışmada, pandemi dönemindeki kısıtlamalar nedeni ile eğitimde ortaya çıkan firsat eşitsizliğinin bir nebze önüne geçebilmek ve mevcut duruma yönelik farkındalık oluşturabilmek adına, öğrencilerin motivaston ihtiyaçları doğrultusunda bir mentore ihtiyaç duyup duymadıklarını makine öğrenmesi yöntemleri ile tespit eden bir çalışma yürütülmüştür. Çalışma ile motivasyonun artırılıp eğitim kalitesinin pandemi sürecinden en az etkilenebilecek, öğrencilere kısıtlamalar karşısında adil bir eğitim/öğretim olanağı sunabilecek bir sistem kullanımına dönüştürülebilmesi hedeflenmektedir. Çalışma kapsamında Ürdün Üniversitesi tarafından pandemi döneminde uzaktan eğitim gören öğrencilere doldurtulan anketler kullanılmıştır. Pandemi koşulları düşünüldüğünde her kurumun tüm öğrencilere uzun anketler yapma olasılığının düşük olduğu göz önüne alınarak, yapay zekanın açıklanabilirliği kapsamında, mentor gerekliliğinin en etkili belirleyicileri tespit edilmiştir. Böylece daha az miktarda belirleyici ile de başarılı mentor gerekliliği tespiti yapılabilmesine olanak sağlanmıştır.

\section{Kaynakça}

Bingöl Schrijer, B . (2020). COVID-19 Salgını Süresince Eğitim Hakk1, Fırsat Eşitliği ve Sınavlara İlişkin Temel Problemler . İstanbul Hukuk Mecmuası , 78 (2) , 837-884 . DOI: 10.26650/mecmua.2020.78.2.0019

Bostan, S., Erdem, R., Öztürk, Y. E., Kılıç, T., \& Yılmaz, A. (2020). The Effect of COVID-19 Pandemic on the Turkish Society. Electronic Journal of General Medicine, 17(6), em237. https://doi.org/10.29333/ejgm/7944

Atasoy, R., Özden, C., \& Kara, D. N. (2020). Covid-19 Pandemi Sürecinde Yapılan E-Ders Uygulamalarının Etkililiğinin Öğrencilerin Perspektifinden Değerlendirilmesi. Electronic Turkish Studies, 15(6).
Tohidi, H., \& Jabbari, M. M. (2012). The effects of motivation in education. Procedia-Social and Behavioral Sciences, 31, 820824.

Dede, Y., \& Argün, Z. (2004). Öğrencilerin matematiğe yönelik içsel ve dışsal motivasyonlarının belirlenmesi. Eğitim ve Bilim, 29(134).

Aboagye, E., Yawson, J. A., \& Appiah, K. N. (2021). COVID-19 and E-learning: The challenges of students in tertiary institutions. Social Education Research, 1-8.

Horita, R., Nishio, A., \& Yamamoto, M. (2021). The effect of remote learning on the mental health of first year university students in Japan. Psychiatry Research, 295, 113561.

Cicha, K., Rizun, M., Rutecka, P., \& Strzelecki, A. (2021). COVID-19 and Higher Education: First-Year Students' Expectations toward Distance Learning. Sustainability 2021, $13,1889$.

Andrews, M., \& Wallis, M. (1999). Mentorship in nursing: a literature review. Journal of advanced nursing, 29(1), 201207.

Lee, L. M., \& Bush, T. (2003). Student mentoring in higher education: Hong Kong Baptist University. Mentoring \& Tutoring, 11(3), 263-271.

Wilkes, Z. (2006). The student-mentor relationship: a review of the literature. Nursing standard, 20(37).

Garcia-Melgar, A., East, J., \& Meyers, N. (2021). Peer assisted academic support: a comparison of mentors' and mentees' experiences of a drop-in programme. Journal of Further and Higher Education, 1-14.

Müller, A. M., Goh, C., Lim, L. Z., \& Gao, X. (2021). COVID19 Emergency eLearning and Beyond: Experiences and Perspectives of University Educators. Educ. Sci. 2021, 11, 19.

Tibingana-Ahimbisibwe, B., Willis, S., Catherall, S., Butler, F., $\&$ Harrison, R. (2020). A systematic review of peer-assisted learning in fully online higher education distance learning programmes. Open Learning: The Journal of Open, Distance and e-Learning, 1-22.

Fayram, J., Boswood, N., Kan, Q., Motzo, A., \& Proudfoot, A. (2018). Investigating the benefits of online peer mentoring for student confidence and motivation. International Journal of mentoring and Coaching in Education. 
Packham, G., \& Miller, C. (2000). Peer-assisted student support: a new approach to learning. Journal of Further and Higher Education, 24(1), 55-65.

Ruane, R. (2012). A study of student interaction in an online learning environment specially crafted for cross-level peer mentoring. Drexel University.

Dias, S. B., Hadjileontiadou, S. J., Diniz, J., \& Hadjileontiadis, L. J. (2020). DeepLMS: a deep learning predictive model for supporting online learning in the Covid-19 era. Scientific reports, 10(1), 1-17.

Agarwal, A., Sharma, S., Kumar, V., \& Kaur, M. (2021). Effect of E-learning on public health and environment during COVID-19 lockdown. Big Data Mining and Analytics, 4(2), 104-115.

Ahmed, A. S. A. M. S., \& Malik, M. H. (2020, November). Machine Learning for Strategic Decision Making during COVID-19 at Higher Education Institutes. In 2020 International Conference on Decision Aid Sciences and Application (DASA) (pp. 663-668). IEEE.

Lu, D. N., Le, H. Q., \& Vu, T. H. (2020). The Factors Affecting Acceptance of E-Learning: A Machine Learning Algorithm Approach. Education Sciences, 10(10), 270.

Feldman, M. D., Arean, P. A., Marshall, S. J., Lovett, M., \& O'Sullivan, P. (2010). Does mentoring matter: results from a survey of faculty mentees at a large health sciences university. Medical education online, 15(1), 5063.

Rodger, S., \& Tremblay, P. F. (2003). The Effects of a Peer Mentoring Program on Academic Success among First Year University Students. Canadian Journal of Higher Education, 33(3), 1-17.

van Esch, C., Luse, W., \& Bonner, R. L. (2021). The impact of COVID-19 pandemic concerns and gender on mentor seeking behavior and self-efficacy. Equality, Diversity and Inclusion: An International Journal.

Xu, Y., Tsao, Y., Shih-Wei, C., Ching-Chang, L., Yen, K. T., \& Tsai, H. Y. (2020). Effect of e-learning environmental stimuli on learning engagement in the context of COVID-19. Revista Argentina de Clínica Psicológica, 29(5), 538.

Kapasia, N., Paul, P., Roy, A., Saha, J., Zaveri, A., Mallick, R., ... $\&$ Chouhan, P. (2020). Impact of lockdown on learning status of undergraduate and postgraduate students during COVID19 pandemic in West Bengal, India. Children and Youth Services Review, 116, 105194.

Al-Okaily, M., Alqudah, H., Matar, A., Lutfi, A., \& Taamneh, A. (2020). Dataset on the Acceptance of e-learning System among Universities Students' under the COVID-19 Pandemic Conditions. Data in brief, 32, 106176.

Al-Okaily et al. (2020), Mendeley Data Repository, Available: https://bit.ly/3i8KkI5 